\title{
Cognitive decline in prostate cancer patients undergoing ADT: a potential role for exercise training
}

\author{
Niamh L Mundell, Robin M Daly, Helen Macpherson and Steve F Fraser \\ Institute for Physical Activity and Nutrition, School of Exercise and Nutrition Sciences, Deakin University, \\ Geelong, Victoria, Australia
}

Correspondence should be addressed to N L Mundell

Email

niamh.mundell@deakin. edu.au

\begin{abstract}
Androgen deprivation therapy (ADT) is an effective and widely prescribed treatment for prostate cancer (PCa), but it is associated with multiple treatment-induced adverse effects that impact on various musculoskeletal and cardiometabolic health outcomes. Emerging research has shown that ADT is also associated with cognitive impairment, which has been linked to a loss of independence, increased falls and fracture risk and greater use of medical services. The aim of this review is to outline the evidence related to the effect of ADT use on cognitive function, and propose a role for exercise training as part of usual care to prevent and/or manage cognitive impairments for PCa survivors on ADT. The following results have been obtained from this study. ADT has been shown to adversely affect specific cognitive domains, particularly verbal memory, visuomotor function, attention and executive function. However, current clinical guidelines do not recommend routine assessment of cognitive function in these men. No studies have examined whether exercise training can preserve or improve cognitive function in these men, but in healthy adults', multimodal exercise training incorporating aerobic training, progressive resistance training (PRT) and challenging motor control exercises have the potential to attenuate cognitive decline. In conclusion, as treatment with ADT for men with PCa has been associated with a decline in cognition, it is recommended that cognitive function be routinely monitored in these men and that regular exercise training be prescribed to preserve (or improve) cognitive function. Assessment of cognition and individualised exercise training should be considered in the usual treatment plan of PCa patients receiving $A D T$.
\end{abstract}

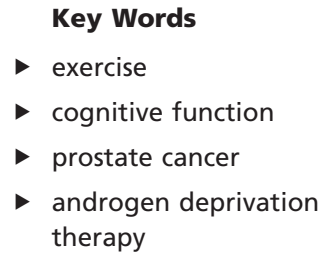

Key Words

- cognitive function

- prostate cancer therapy
Endocrine-Related Cancer (2017) 24, R145-R155

\section{Introduction}

Prostate cancer (PCa) is the most prevalent nondermatological male cancer globally (Australian Institute of Health and Welfare 2014). Despite improved PCa survivorship, men suffer a range of adverse effects from treatment. Androgen deprivation therapy (ADT) is a commonly prescribed treatment that reduces androgens, such as testosterone, to castration levels in an attempt to slow tumour progression and improve overall survival in men with appropriately selected locally advanced and metastatic disease (Grossmann et al. 2013). ADT prescription has increased for all stages and grades of PCa (Shahinian et al. 2005). Despite improving survival, research has consistently reported a range of adverse effects associated with the use of ADT including deterioration in

Published by Bioscientifica Ltd. 
musculoskeletal health, an increase in cardiometabolic risk and a reduction in health-related quality of life (HR-QoL) (Gardner et al. 2014). A growing body of evidence indicates that ADT may also adversely affect cognitive function, including information processing (Green et al. 2002), spatial abilities (Cherrier et al. 2009) and memory (Bussiere et al. 2005), visuo-motor speed (McGinty et al. 2014) and executive function (Cherrier et al. 2009). However, current guidelines for the assessment and management of PCa for men treated with ADT do not recommend an assessment of cognitive function or methods for attenuating cognitive decline associated with treatment (Bussiere et al. 2005, Grossmann \& Zajac 2011). There is emerging evidence that exercise training can play an important role in minimising the risk of cognitive deterioration with advancing age in healthy older adults (Colcombe \& Kramer 2003). Importantly, regular exercise may also assist in managing various other adverse effects of ADT, such as cardiometabolic risk, which have been linked to cognitive impairment and related disorders (Papachristou et al. 2015). The aim of this review is to outline the evidence related to the effect of ADT use on cognitive function and propose a role for exercise training as part of usual care to prevent and/or manage cognitive impairments for PCa survivors on ADT.

\section{The effects of androgen deprivation on cognitive function}

Cognitive decline is part of the normal ageing process, particularly in the domains of information processing speed, memory, reasoning, reaction time and spatial abilities (Salthouse 2009). However, in men with PCa treated with ADT, the rate of decline in these processes appears to be accelerated (McGinty et al. 2014). Furthermore, the use of ADT has been associated with an almost two-fold increased risk for developing Alzheimer's disease $(\mathrm{AD})$, with the risk increasing with treatment duration (Nead et al. 2016). Thirteen prospective studies have objectively assessed cognitive function in patients receiving ADT (Table 1) (Green et al. 2002, 2004, Cherrier et al. 2003, 2009, 2010, Salminen et al. 2003, Almeida et al. 2004, Alibhai et al. 2010, Matousek \& Sherwin 2010, Mohile et al. 2010, Chao et al. 2012, Tan et al. 2013, Gonzalez et al. 2015). Five of these studies reported no effect (Almeida et al. 2004, Matousek \& Sherwin 2010, Mohile et al. 2010, Chao et al. 2012, Tan et al. 2013), which is likely related in part to methodological differences in participant characteristics, study design and analyses. For instance, four of the 11 studies did not include non-ADT control participants (Almeida et al. 2004, Matousek \& Sherwin 2010, Mohile et al. 2010, Tan et al. 2013).

Longitudinal studies of men with various cancers have identified that $16-48 \%$ had lower-than-normal cognitive performance prior to cancer treatment (Janelsins et al. 2014, Wefel et al. 2015). As cognitive function is rarely measured prior to ADT administration, many studies are observational, and few studies have provided a measure of estimated cognitive reserve. This is important because cognitive reserve provides a retrospective estimated baseline for cognitive function (Roldán-Tapia et al. 2012), and the degree of cognitive decline can be a function of ADT treatment duration (Nead et al. 2016). The National Adult Reading Test (NART), which provides a measure of reading intelligence that is more stable over time than other facets of intelligence, is one example of a relatively simple and easy-to-administer neurocognitive instrument that estimates cognitive reserve (Bright et al. 2016). To determine the cognitive performance in PCa survivors on ADT, standardised, objective measures of cognitive domains shown to be affected by ADT should be included (Wefel et al. 2011).

As indicated earlier, there is a growing body of evidence that ADT can accelerate cognitive decline; however, there has been only one longitudinal randomised controlled trial (RCT) examining cognitive function in men with $\mathrm{PCa}$ prior to and during ADT administration that also included a non-ADT control group (Green et al. 2002). Green and coworkers (Green et al. 2002) objectively assessed cognitive function in 77 men (mean age; 73 years) with PCa prior to commencing ADT, and six months after random allocation to ADT, or a watchful waiting control (Green et al. 2002). In 24 of the 50 men randomised to $\mathrm{ADT}$, significant declines were evident in one or more cognitive tests at 6 months when compared to non-ADT controls, who showed no cognitive decline (Green et al. 2002). Importantly, the ADT group did not show a practice effect in comparison to the non-ADT controls, which may indicate a lack of learning ability (Green et al. 2002). A limitation of this study was the absence of a healthy control group, thus, potential cognitive effects linked to the cancer itself were not differentiated from the potential adverse effects of ADT (Wefel et al. 2011). Nevertheless, these findings highlight the negative influence of ADT on certain cognitive domains, including visuomotor control, verbal fluency, verbal memory, visual memory and attention (Green et al. 2002). 
Table 1 Characteristics of longitudinal studies objectively assessing cognitive function in prostate cancer survivors on androgen deprivation therapy (ADT).

\begin{tabular}{|c|c|c|c|c|c|c|c|}
\hline Study & $\begin{array}{c}\text { PCa } \\
\text { ADT } \\
(N) \\
\end{array}$ & $\begin{array}{c}\text { PCa } \\
\text { controls } \\
(N) \\
\end{array}$ & $\begin{array}{l}\text { Healthy } \\
\text { controls } \\
(N)\end{array}$ & $\begin{array}{c}\text { Study } \\
\text { duration } \\
\text { (months) }\end{array}$ & $\begin{array}{c}\text { Mean } \\
\text { age } \\
\text { (years) }\end{array}$ & Cognitive domains tested & Outcomes \\
\hline Alibhai et al. (2010) & 77 & 82 & 82 & 12 & 69 & $\begin{array}{l}\text { Attention, processing speed, } \\
\text { verbal fluency, visuospatial } \\
\text { ability, executive functions }\end{array}$ & $\begin{array}{l}\text { Possible lack of learning effect, } \\
\text { no consistent evidence for } \\
\text { adverse effects to cognitive } \\
\text { function }\end{array}$ \\
\hline Almeida et al. (2004) & 37 & NA & NA & 9 & 72 & $\begin{array}{l}\text { Verbal memory, verbal fluency, } \\
\text { visual memory, visuomotor } \\
\text { ability, visuospatial ability, } \\
\text { working memory, attention }\end{array}$ & $\begin{array}{l}\text { No effect in any domain tested. } \\
\text { Improvements in memory } \\
\text { after treatment } \\
\text { discontinuation }\end{array}$ \\
\hline Chao et al. (2012) & 18 & 18 & NA & 6 & 69 & $\begin{array}{l}\text { Working memory, cognitive } \\
\text { control }\end{array}$ & $\begin{array}{l}\text { No effect on cognitive test } \\
\text { scores. Decreased functional } \\
\text { connectivity during resting } \\
\text { state fMRI, decreased cortical } \\
\text { activation during cognitive } \\
\text { control tasks }\end{array}$ \\
\hline Mohile et al. (2010) & 21 & NA & NA & 6 & 71 & $\begin{array}{l}\text { Verbal fluency, verbal memory, } \\
\text { visual memory, working } \\
\text { memory, visuomotor ability, } \\
\text { fine motor }\end{array}$ & No effect in any domain tested \\
\hline Salminen et al. (2004) & 25 & NA & 52 & 12 & 65 & $\begin{array}{l}\text { Verbal fluency, verbal memory, } \\
\text { visual memory, visuospatial } \\
\text { ability, visuomotor ability, } \\
\text { working memory, spatial } \\
\text { memory, attention }\end{array}$ & $\begin{array}{l}\text { Visuomotor slowing, slowed } \\
\text { reaction times in working } \\
\text { memory, impaired hit rate in a } \\
\text { vigilance test, impaired } \\
\text { delayed recall and recognition } \\
\text { speed of letters, improvement } \\
\text { in object recall }\end{array}$ \\
\hline Tan et al. (2013) & 24 & NA & NA & 12 & 71 & Verbal memory, learning & No effect in any domain tested \\
\hline Cherrier et al. (2003) & 19 & NA & 15 & 12 & 65 & $\begin{array}{l}\text { Verbal fluency, verbal memory, } \\
\text { spatial memory, visuospatial } \\
\text { ability, attention }\end{array}$ & $\begin{array}{l}\text { Significant declines in } \\
\text { visuospatial ability and spatial } \\
\text { memory, improved story recall }\end{array}$ \\
\hline Cherrier et al. (2009) & 19 & NA & 19 & 12 & 64 & $\begin{array}{l}\text { Verbal fluency, verbal memory, } \\
\text { visual memory, visuospatial } \\
\text { ability, spatial memory, } \\
\text { attention }\end{array}$ & $\begin{array}{l}\text { Significant declines in } \\
\text { visuospatial ability, spatial } \\
\text { memory and attention }\end{array}$ \\
\hline Cherrier et al. (2010) & 5 & NA & 7 & 9 & 65 & $\begin{array}{l}\text { Visuospatial ability and spatial } \\
\text { memory }\end{array}$ & $\begin{array}{l}\text { Reduced task-related BOLD- } \\
\text { fMRI activation during mental } \\
\text { manipulation and spatial } \\
\text { recall }\end{array}$ \\
\hline Green et al. (2002) & 77 & 15 & NA & 6 & 73 & $\begin{array}{l}\text { Verbal fluency, verbal memory, } \\
\text { visual memory, attention }\end{array}$ & $\begin{array}{l}\text { Significant declines in verbal } \\
\text { memory, attention and } \\
\text { executive function }\end{array}$ \\
\hline Green et al. (2004) & 37 & 14 & 15 & 12 & 72 & $\begin{array}{l}\text { Verbal memory, visual memory, } \\
\text { working memory, attention }\end{array}$ & $\begin{array}{l}\text { Significant declines in verbal } \\
\text { memory, coding and } \\
\text { inhibitory tasks }\end{array}$ \\
\hline Gonzalez et al. (2015) & 58 & 84 & 88 & 12 & 68 & $\begin{array}{l}\text { Verbal memory, visual memory, } \\
\text { attention }\end{array}$ & $\begin{array}{l}\text { No difference in mean } \\
\text { cognitive performance } \\
\text { between groups. ADT patients } \\
\text { were more likely to show } \\
\text { impairment in one or two test } \\
\text { categories }\end{array}$ \\
\hline $\begin{array}{l}\text { Matousek \& Sherwin } \\
\quad(2010)\end{array}$ & 21 & NA & NA & 3 & 71 & $\begin{array}{l}\text { Verbal fluency, visuomotor } \\
\text { ability, working memory, } \\
\text { visuospatial ability, attention }\end{array}$ & No effect in any domain tested \\
\hline
\end{tabular}

BOLD, blood oxygenation level dependent; fMRI, functional magnetic resonance imaging; NA, not assessed.

An important question that requires further investigation is whether ADT leads to a greater rate of deterioration in specific cognitive domains. Several studies have reported that spatial memory and spatial ability are often adversely affected by ADT (Cherrier et al. 2003, 2009, Jenkins et al. 2005). Other studies have reported adverse 
effects of ADT on spatial memory, spatial ability, verbal memory and working memory (Table 1) (Green et al. 2002, 2004, Salminen et al. 2003, Cherrier et al. 2010), with reports that at least one of these measures of cognitive function decline by $47-69 \%$ in men on ADT over 9-12 months (Cherrier et al. 2003, Jenkins et al. 2005). Brain imaging studies have also shown that the adverse effects to spatial ability and memory are related to changes in cerebral function and brain volume (Cherrier et al. 2009, Chao et al. 2012, 2013). However, a meta-analysis of 14 studies that objectively measured cognitive function in PCa survivors on ADT confirmed that the largest effect size in relation to ADT and cognitive function was for the visuomotor control domain (effect size, $g=-0.67$ ) (McGinty et al. 2014), which may indicate an effect of reduced testosterone on tasks involving both vision and manual manipulation.

One of the challenges in comparing the results across different studies is the inconsistent definitions used for cognitive impairment or decline. For example, Mohile and coworkers (Mohile et al. 2010) defined cognitive impairment as scoring $>1.5$ standard deviation (s.D.) below the age- and education-adjusted population reference means (Mohile et al. 2010). Alibhai and coworkers (Alibhai et al. 2010) defined cognitive decline as a reduction of at least one S.D. in at least one cognitive test (Alibhai et al. 2010), whereas Gonzalez and coworkers (Gonzalez et al. 2015) defined impaired cognitive performance as a score $>1.5$ S.D. below population norms on two or more tests or $>2$ S.D. below published norms on one test (Wefel et al. 2011, Gonzalez et al. 2015). A more consistent interpretation of cognitive impairment would assist in evaluating the effects of ADT on cognitive performance (Gonzalez et al. 2015). However, recent longitudinal trials have shown greater rigour in test selection (for example including the NART, Hopkins verbal learning test, digit span and controlled oral word association test) and study design for assessing cognitive function in PCa patients, which assists with the validity of inter-study comparisons (Gonzalez et al. 2015).

In summary, the available evidence indicates that ADT adversely affects the cognitive domains of verbal, visual, spatial and working memory (Green et al. 2002, 2004, Beer et al. 2006, Cherrier et al. 2009), spatial reasoning and spatial ability (Cherrier et al. 2003, 2009), psychomotor and visuomotor function (Green et al. 2004, Salminen et al. 2004), auditory learning (Bussiere et al. 2005), executive function and processing speed (Green et al. 2002, 2004, Cherrier et al. 2009), with the most significant effects on visuomotor ability (McGinty et al. 2014). Given that a randomised study design of ADT use is not ethical for men with advanced PCa, future observational studies that aim to measure cognitive function in PCa patients should closely adhere to current guidelines for assessing the cognitive function in cancer patients, such as those recommended by the International Cognition and Cancer Task Force (ICCTF) (Wefel et al. 2011). A brief overview of these guidelines will be discussed below.

\section{Ethical approval}

This article does not contain any studies with human participants or animals performed by any of the authors.

\section{Guidelines for assessing cognitive function in prostate cancer patients}

Neuropsychological assessment is indicated where treatment for a disease influences cognitive function and should be performed by (or under the guidance of) a psychologist (Harvey 2012). It is important to supplement cognitive function testing with the assessment of other factors that may contribute to cognitive dysfunction, such as mood and motivational state (Harvey 2012). In men treated with ADT, consideration should also be given to the effects of confounding variables such as age, education levels, depressive symptoms, fatigue and hot flash interference (Nelson et al. 2008, Gonzalez et al. 2015). The ICCTF guidelines for the assessment of cognitive function in chemotherapy patients (Wefel et al. 2011) have also been applied in patients with PCa (Gonzalez et al. 2015) and recommend that validated, objective measures of cognitive function be used in cancer patients, which assess those domains shown to be affected (Wefel et al. 2011). Where possible, clinical significance should be determined according to the respective norms or cut points for each specific neurological test (Wefel et al. 2011). Impaired cognitive performance should be uniformly determined by a performance of 1.5 s.D. below population norms on two or more tests or 2 S.D. below published norms on one test (Wefel et al. 2011). Cognitive test selection should include objective tests that have been previously shown to differentiate the effects of ADT in PCa survivors (Wefel et al. 2011) and which include specific cognitive domains such as visuomotor and visuospatial ability, attention, working memory, spatial memory, spatial ability, verbal memory and executive functions (Green et al. 2002, 2004, Cherrier et al. 2003, 2009, Salminen et al. 2004, Bussiere et al. 2005, Beer et al. 2006). Commonly used neuropsychological tests of

Published by Bioscientifica Ltd 
Table 2 Domains of cognitive function and common neuropsychological tests used to assess each domain.

\section{Domains of cognitive function}

Processing speed

Executive functions

Memory

Verbal and semantic memory

Working memory

Working memory

Language

Visuo-spatial ability

The ability to perceive and interpret visuo-spatia information and relationships such as maps or figures

Attention

\section{Description}

Speed of cognitive or perceptual performance

Planning, judgement, problem solving, impulse control, and abstract reasoning. Important for goal oriented behaviour, including performance monitoring, goal setting, and adjust of behaviour in response to feedback

Visual memory

Episodic memory - personally experienced events; antegrade, retrograde

Procedural memory

The ability to acquire and retain verbal information, for example verbal lists or instructions word meaning and general knowledge

Temporary information storage, mental manipulation of information

Temporary information storage, mental manipulation of information

Naming, repetition, comprehension, reading, writing

Ability to maintain a consistent behavioural response throughout a consistent or repetitive behaviour, and avoid irrelevant stimuli

\section{Neurocognitive tests}

- Trail making test A

- Simple and choice reaction time

- Symbol digit modalities test - written and oral

- Conditional associative learning test

- D-KEFS color-word interference test

- Digit symbol substitution (WAIS-R; WAIS-III) letter-number sequencing (WAIS-III)

- Stroop color word interference task

- Symbol digit modalities test

- Trail making test B

- Nonverbal selective reminding test

- Continuous recognition memory test

- Brief visuospatial memory test

- Object recall

- Rey-Osterrieth complex figure delayed recall visual memory index (WMS-R)

- Visual reproduction (WMS-III)

- WMS-III visual memory index

- California verbal learning test II

- Hopkins verbal learning test

- Logical memory task (WMS-R)

- Proactive interference

- Rey auditory verbal learning test

- Toronto word pool (encoding, retention, and recognition) verbal memory index (WMS-R)

- Verbal paired associates (WMS-R; WMS-III)

- Word list recall

- Word lists (WMS-III)

- Attention and concentration index (WMS-R)

- Digit span forward and backward (WAIS-III; WMS-III) spatial span forward and backward (WMS-III)

- Subject-ordered pointing test

- Attention and concentration index (WMS-R)

- Digit span forward and backward (WAIS-III; WMS-III) spatial span forward and backward (WMS-III)

- Spatial working memory task

- Subject-ordered pointing test

- Subtraction

- Animal fluency

- Controlled oral word association test

- Letter word fluency

- Object naming

- Picture naming

- Similarities (WAIS-III)

- Vocabulary (WAIS-R)

- Block design (WAIS-R; WAIS-III)

- Paper folding test

- Rey-Osterrieth complex figure copy

- Judgment of line orientation

- Hooper visual organization test

- Attention and Concentration Index (WMS-R)

- Digit span forward and backward (WAIS-III; WMSIII) spatial span forward and backward (WMS-III)

- Spatial working memory task

- Subject-ordered pointing test

- Subtraction

- Trail making test A

- Vigilance 
Table 2 Continued.

Domains of cognitive

function

Visuo-motor ability
Description

Synchronization of visual perception and motor skills

\section{Neurocognitive tests}

- Card rotations

- Environmental memory task encoding and recognition judgment of line orientation

- Puget sound route learning test

- Vandenberg and Kuse mental rotation test

- Visuo-motor integration test - block design

Data from Kulkarni \& Moningi (2015) and McGinty et al. (2014).

D-KEFS, Delis-Kaplan executive function system; WAIS-R, Wechsler adult intelligence scale-revised; WAIS-III, Wechsler adult intelligence scale-third edition; WMS-R, Wechsler memory scales-re-vised edition; WMS-III, Wechsler memory scales-third edition.

cognitive function which meet these criteria are shown in Table 2.

\section{Effects of exercise training on cognitive function in men on ADT}

Although exercise has been shown to be important for the prevention and management of cognitive impairment in cancer patients generally (Zimmer et al. 2016), various reviews have also associated exercise interventions with improved cognitive function in men treated with ADT (Trost et al. 2013, Ahmadi \& Daneshmand 2014, Gardner et al. 2014, Nguyen et al. 2015). However, as shown in Table 3, many of these exercise trials are limited by the use of a generalised quality of life (QoL) questionnaire containing subjective measures of cognitive function, such as the European Organization for Research and Treatment of Cancer quality of life questionnaire (EORTCQLQ C30) (Culos-Reed et al. 2007, 2010, Livingston et al. 2011, Oh et al 2012, Cormie et al. 2014a, Buffart et al. 2015). Subjective reports of cognitive function have not been validated as a means to assess cognitive function in cancer patients and are more closely associated with mood than objective measures of cognitive function (Wefel et al. 2011).

There is currently little evidence available to support the benefits of exercise training for improving cognitive function in PCa survivors receiving ADT, but the results from studies of older adults and non-PCa cancer survivors are promising. Meta-analyses indicate that exercise can reduce the risk for developing dementia and $\mathrm{AD}$ by $28 \%$ and $45 \%$, respectively, with the volume of exercise training inversely related to dementia risk (Hamer \& Chida 2009). Indeed, greater cardiovascular fitness has shown to be positively associated with cognitive performance in older adults (mean 0.5 s.D. benefit), independent of cognitive task type, exercise training method or participants' characteristics (Colcombe \& Kramer 2003).
The mechanisms underlying these improvements in cognitive function may relate to changes in brain structure. For example, an RCT of 120 healthy older adults (mean age 67 years) found that aerobic exercise training was associated with improved spatial memory and hippocampal volume in comparison to a nonexercising control (Erickson et al. 2011). In another RCT including 120 older adults (mean age 67 years) who completed 12 months of aerobic exercise training (10-40 min of walking at $50-75 \%$ maximum heart rate reserve) that increased cardiovascular fitness, there was a corresponding increase in hippocampal volume; an area of the brain which is vulnerable to age-related degradation (Erickson et al. 2011). Collectively, these findings provide some evidence that aerobic training that is associated with an improvement in fitness may lead to an improvement in cognitive function in older people.

More recent research has found that progressive resistance training (PRT) and multimodal exercise programmes incorporating aerobic and resistance training can also aid cognitive function in older adults (Liu-Ambrose et al. 2010, Nagamatsu et al. 2012, Fragala et al. 2014). For instance, moderate-to-highintensity PRT (70-85\% of one-repetition maximum (1-RM)) has been shown to improve memory and attention in older men (Cassilhas et al. 2007) and spatial awareness in older adults (Fragala et al. 2014). Combined or multimodal exercise interventions that include a motor component (movement speed, balance, motor coordination and flexibility) have also been shown to improve cognitive function in older adults (VoelckerRehage et al. 2010). Although questions still remain as to the optimal type and dose of exercise that is most effective to improve cognitive function in older adults, a meta-analysis of single or bimodal exercise trials indicated a small-to-moderate effect on cognitive performance with combined aerobic and PRT compared to aerobic training alone in older adults (Colcombe \& Kramer 2003).

Published by Bioscientifica Ltd 
Table 3 Interventions examining the effects of exercise training on cognitive function in men with PCa treated with androgen deprivation therapy (ADT).

\begin{tabular}{|c|c|c|c|c|c|c|}
\hline Author (year) & Study design & Population & $\begin{array}{l}\text { Intervention: } \\
\text { PCa control: } \\
\text { healthy } \\
\text { control }(n)\end{array}$ & $\begin{array}{l}\text { Subjective } \\
\text { cognitive } \\
\text { measures }\end{array}$ & $\begin{array}{l}\text { Exercise } \\
\text { intervention }\end{array}$ & Results \\
\hline $\begin{array}{l}\text { Buffart et al. } \\
\text { (2015) }\end{array}$ & RCT 12 months & $\begin{array}{l}\mathrm{PCa} \\
\mathrm{ADT}+\text { radiotherapy } \\
N=100\end{array}$ & 50:50:NA & EORTC QLQ-C30 & $\begin{array}{l}\text { RT and aerobic } \\
\text { exercise } \\
12 \text { months vs } \\
\text { educational } \\
\text { material }\end{array}$ & $\begin{array}{l}\text { A statistically } \\
\text { significant } \\
\text { improvement in } \\
\text { subjective } \\
\text { cognitive scores } \\
\text { at } 6 \text { months }\end{array}$ \\
\hline $\begin{array}{l}\text { Cormie et al. } \\
(2014 a, b)\end{array}$ & RCT 12 weeks & $\begin{array}{l}\text { PCa, BCa + mets } \\
\quad N=20\end{array}$ & 10:10:NA & MFSI SF & $\begin{array}{l}\text { Group RT, } \\
\text { aerobic } \\
\text { exercise and } \\
\text { stretching, } \\
60 \text { min } \\
\text { duration twice } \\
\text { per week }\end{array}$ & $\begin{array}{l}\text { No significant } \\
\text { improvement in } \\
\text { fatigue related } \\
\text { mental scores }\end{array}$ \\
\hline $\begin{array}{l}\text { Culos-Reed et al. } \\
\text { (2010) }\end{array}$ & RCT 16 weeks & $\mathrm{PCa}+\mathrm{ADT} N=100$ & 53:47:NA & EORTC QLQ-C30 & $\begin{array}{l}\text { Home based } \\
\text { aerobic and RT } \\
3-5 \text { times/week }\end{array}$ & $\begin{array}{l}\text { Subjective } \\
\text { cognitive scores } \\
\text { not reported }\end{array}$ \\
\hline $\begin{array}{l}\text { Culos-Reed et al. } \\
(2007)\end{array}$ & $\begin{array}{l}\text { RCT } 12 \text { weeks, } \\
4 \text { month follow up }\end{array}$ & $\mathrm{PCa}+\mathrm{ADT} N=31$ & 18:13:NA & EORTC QLQ-C30 & $\begin{array}{l}\text { Home based } \\
\text { aerobic and RT } \\
3-5 \text { times/week } \\
\text { plus a biweekly } \\
\text { booster of } \\
60 \text { min exercise } \\
\text { and } 30 \text { min of } \\
\text { education }\end{array}$ & $\begin{array}{l}\text { Subjective } \\
\text { cognitive scores } \\
\text { not reported }\end{array}$ \\
\hline $\begin{array}{l}\text { Galvão et al. } \\
\text { (2010) }\end{array}$ & $\mathrm{RCT} 12$ weeks & $\mathrm{PCa}+\mathrm{ADT} N=57$ & 29:28:NA & EORTC QLQ-C30 & $\begin{array}{l}\text { Group aerobic } \\
\text { and RT, twice/ } \\
\text { week }\end{array}$ & $\begin{array}{l}\text { Significant } \\
\text { improvement in } \\
\text { subjective } \\
\text { cognitive scores }\end{array}$ \\
\hline $\begin{array}{l}\text { Livingston et al. } \\
\text { (2015) }\end{array}$ & $\begin{array}{l}\text { RCT } 12 \text { weeks }+3,6 \\
\text { and } 12 \text { month } \\
\text { follow up }\end{array}$ & PCa $N=147$ & 54:93:NA & $\begin{array}{l}\text { EORTC } \\
\text { QLQ-PR25, } \\
\text { EORTC } \\
\text { QLQ-C30 }\end{array}$ & $\begin{array}{l}\text { Moderate to } \\
\text { strenuous } \\
\text { physical } \\
\text { activity, } 3 \\
\text { times/week } \\
\text { (150 min) }\end{array}$ & $\begin{array}{l}\text { Significant } \\
\text { improvement in } \\
\text { subjective } \\
\text { cognitive scores }\end{array}$ \\
\hline $\begin{array}{l}\text { Miki et al. } \\
(2014)\end{array}$ & RCT 4 weeks & $\mathrm{PCa}, \mathrm{BCa} N=78$ & 38:40:NA & $\mathrm{FAB}$ & $\begin{array}{l}\text { Speed-feedback } \\
\text { training, two } \\
\text { five-minute, } \\
\text { low intensity } \\
\text { sessions per } \\
\text { week with } \\
\text { cognitive task }\end{array}$ & $\begin{array}{l}\text { Improved } \\
\text { prefrontal } \\
\text { functions }\end{array}$ \\
\hline Oh et al. (2012) & RCT 10 weeks & $\begin{array}{l}\mathrm{PCa}, \mathrm{BCa}, \mathrm{LCa}, \\
\text { colorectal, stomach } \\
\text { cancer } N=81\end{array}$ & $37: 44: N A$ & $\begin{array}{l}\text { EORTC QLQ-C30, } \\
\text { FACT-Cog }\end{array}$ & $\begin{array}{l}\text { Medical Qigong } \\
2 \text { times/week for } \\
90 \mathrm{~min}\end{array}$ & $\begin{array}{l}\text { Intervention } \\
\text { group improved } \\
\text { on all subjective } \\
\text { cognitive } \\
\text { measures }\end{array}$ \\
\hline
\end{tabular}

BCa, breast cancer; EORTC QLQ-C30, European Organization for Research and Treatment of Cancer, quality of life questionnaire; FAB, frontal assessment battery; FACT-Cog, functional assessment of cancer therapy-cognitive function; FSS, fatigue severity scale; LCa, lung cancer; MFSI SF, moderate fatigue severity index short-form; NA, not applicable; PCa, prostate cancer; RCT, randomised controlled trial; RT, resistance training.

Others have reported that more intense exercise leads to a greater effect on subsequent cognitive performance than light or moderate exercise (Chang et al. 2012).

Longer duration interventions (6-12 months) have also been associated with improved neural connectivity and activation in the brain in older adults (Voss et al. 2010). For example, one-year long study compared aerobic exercise training for 10-40 min three times per week at $50-75 \%$ maximum heart rate reserve $(n=30)$ to moderate intensity stretching and balance 
exercises $(n=35)$ on neural connectivity and cognitive functions in older adults (median age 67.5 years, median $\mathrm{VO} 2$ peak $21 \mathrm{~mL} / \mathrm{kg} / \mathrm{min}$ ) and reported significant withingroup improvements in measures of neural connectivity in brain networks vulnerable to dysfunction with ageing in the aerobic training group (Voss et al. 2010). Furthermore, these changes were positively correlated with changes in executive function in the aerobic training group, but the stretching/balance group also showed alterations in functional connectivity, possibly representing experience-dependent plasticity (Voss et al. 2010). These findings may be relevant to men with PCa treated with ADT as there is some evidence from a study of 30 PCa survivors (median age 68 years), which found that 6 months of ADT was associated with decreased grey matter volume, reduced brain functional connectivity and reduced neural activations during cognitive control tasks (Chao et al. 2012, 2013).

Collectively, the current evidence indicate that regular exercise training can offer protective benefits to cognitive function in healthy older adults, but in men with PCa receiving ADT, the direct link between exercise and cognitive function has not been established. Given the strength of evidence for cognitive decline associated with ADT use for men with PCa and the confirmed benefits of exercise training for cognitive function in older adults, it is reasonable to infer that these benefits will translate to PCa survivors on ADT. It has previously been shown that PRT can provide substantial benefits to musculoskeletal health in men treated with ADT for PCa (Cormie et al. 2013) and that aerobic training can improve cardiometabolic risk factors that have been implicated in cognitive decline, but the effects of these modes of exercise training on cognitive function have not been assessed in these men. Exercise training can also reduce the risk of developing diabetes, obesity and cardiovascular disease (Roque et al. 2013), which are prevalent in men treated with ADT (Galvão et al. 2009, Keogh \& MacLeod 2012) and are also risk factors for cognitive decline and neurodegeneration (Cotman et al. 2007). Given the need to also redress functional deficits, losses in bone mineral density and muscle mass and increases in cardiometabolic risk factors in PCa survivors on ADT, multimodal exercise programmes which include a combination of aerobic, PRT and motor control components are likely to provide the greatest overall benefits (Voelcker-Rehage et al. 2010, Keogh \& MacLeod 2012).

Although there are currently no data on the effects of exercise training on cognitive function specific to ADT and non-ADT men with $\mathrm{PCa}$, a review of trials in women with breast cancer and mixed cancer types show a positive effect of exercise training on cognitive function (Zimmer et al. 2016). Thus, despite the lack of direct evidence, there is indirect evidence to support a role for exercise training in attenuating the negative effects of ADT on cognitive function. However, given the unique physiological profile of this patient group, there remains a need for more adequately powered RCTs to investigate the effects of exercise on cognitive function in these men. These studies should include the use of objective, standardised measures of cognitive function.

\section{Exercise guidelines for management of ADT adverse effects}

In the management of ADT-related complications, an allied health professional (such as an Accredited Exercise Physiologist in the Australian health care system) should be engaged to assess the patient and individualise exercise prescription (Cheema et al. 2014). The current exercise guidelines for cancer survivors advocate normal daily activities and exercise according to age-appropriate physical activity guidelines during and after nonsurgical treatments, with modifications required in the instance of metastatic bone or cardiac disease (Schmitz et al. 2010). These guidelines do not include specific prescription parameters for addressing the cognitive decline associated with ADT (Schmitz et al. 2010). There is currently insufficient evidence in the literature to guide precise exercise prescription guidelines in terms of the frequency, intensity and duration required for men with PCa treated with ADT to attenuate cognitive decline. With respect to the optimal dose for improving or protecting cognitive function in older adults without PCa, emerging evidence indicates that moderate- and high-intensity $(60-80 \%$ of maximal strength) PRT performed at least twice per week, including at least two sets of 7-10 exercises performed for 2-12 months may positively affect cognitive function (Yu-Kai et al. 2012). However, most of the available data from older adults indicate that the largest effect sizes in terms of exercise training occur with programmes of longer duration ( $>6$ months), sessions of 31-45 min at moderate intensities and consisting of combined aerobic and resistance training performed a minimum of three days per week (Colcombe \& Kramer 2003, Bherer et al. 2013).

Many cancer survivors are motivated to seek advice on optimal lifestyle advice to aid recovery, optimise management of treatment side effects and improve QoL (Rock et al. 2012). Advice given by a health care provider or physician has consistently been shown to

Published by Bioscientifica Ltd. 
facilitate health behaviour changes in cancer patients (Rock et al. 2012). A 12-week RCT including $100 \mathrm{PCa}$ survivors on ADT (mean age; 71 years) indicated that an intervention involving exercise and dietary advice was feasible and induced sustainable behaviour changes after intervention (Bourke et al. 2012). However, advice may be conflicting and unsupported by data (Rock et al. 2012), indicating a need for consistent, evidence-based recommendations.

\section{Conclusion}

There is convincing evidence for the adverse effects of ADT on cognitive function in men treated with ADT for $\mathrm{PCa}$, and appropriately timed cognitive assessment is warranted. When a measure of pre-treatment or prediagnosis cognitive function is not feasible, a reliable measure of estimated cognitive reserve should be implemented at baseline with a battery of neurocognitive tests which comply with ICCTF guidelines (Wefel et al. 2011). Emerging evidence indicates that a structured and targeted exercise intervention focussing on improvements in aerobic fitness, musculoskeletal health and function may have multiple benefits for men treated with ADT in terms of addressing such adverse effects as reduced bone mineral density, an adverse metabolic and cardiac health profile, sexual dysfunction, reduced QoL and changes in body composition (Cormie et al. 2015). Evidence from older, healthy populations supports the role of exercise as being protective against cognitive decline, and exercise guidelines for those with cardiovascular and metabolic disease should be used to inform exercise prescription in PCa survivors treated with ADT who present with such comorbidities. Although these exercise training recommendations are not intended to replace standard care, due consideration to risk for cognitive impairment is recommended for PCa survivors on ADT. Individualised multimodal exercise training is recommended to compliment usual care and may maximise cognitive function for this vulnerable population.

\section{Declaration of interest}

The authors declare that there is no conflict of interest that could be perceived as prejudicing the impartiality of this review.

\section{Funding}

This work did not receive any specific grant from any funding agency in the public, commercial, or not-for-profit sector.

\section{References}

Ahmadi H \& Daneshmand S 2014 Androgen deprivation therapy for prostate cancer: long-term safety and patient outcomes. Patient Related Outcome Measures 5 63-70. (doi:10.2147/PROM.S52788)

Australian Institute of Health and Welfare 2014 Cancer in Australia: An Overview 2014. Canberra, Australia: Australian Institute of Health and Welfare.

Alibhai SMH, Breunis H, Timilshina N, Marzouk S, Stewart D, Tannock I, Naglie G, Tomlinson G, Fleshner N, Krahn M, et al. 2010 Impact of androgen-deprivation therapy on cognitive function in men with nonmetastatic prostate cancer. Journal of Clinical Oncology 28 5030-5037. (doi:10.1200/JCO.2010.30.8742)

Almeida OP, Waterreus A, Spry N, Flicker L \& Martins RN 2004 One year follow-up study of the association between chemical castration, sex hormones, beta-amyloid, memory and depression in men. Psychoneuroendocrinology 29 1071-1081. (doi:10.1016/j. psyneuen.2003.11.002)

Beer TM, Bland LB, Bussiere JR, Neiss MB, Wersinger EM, Garzotto M, Ryan CW \& Janowsky JS 2006 Testosterone loss and estradiol administration modify memory in men. Journal of Urology $\mathbf{1 7 5}$ 130-135. (doi:10.1016/S0022-5347(05)00049-2)

Bherer L, Erickson KI \& Liu-Ambrose T 2013 A review of the effects of physical activity and exercise on cognitive and brain functions in older adults. Journal of Aging Research 2013 1-8. (doi:10.1155/ 2013/657508)

Bourke L, Sohanpal R, Nanton V, Crank H, Rosario DJ \& Saxton JM 2012 A qualitative study evaluating experiences of a lifestyle intervention in men with prostate cancer undergoing androgen suppression therapy. Trials 13 208. (doi:10.1186/1745-6215-13-208)

Bright P, Hale E, Gooch VJ, Myhill T \& van der Linde I 2016 The National Adult Reading Test: restandardisation against the Wechsler adult intelligence scale-fourth edition. Neuropsychological Rehabilitation 14 1-9. (doi:10.1080/09602011.2016.1231121)

Buffart LM, Newton RU, Chinapaw MJ, Taaffe DR, Spry NA, Denham JW, Joseph DJ, Lamb DS, Brug J \& Galvão DA 2015 The effect, moderators, and mediators of resistance and aerobic exercise on health-related quality of life in older long-term survivors of prostate cancer. Cancer 121 2821-2830. (doi:10.1002/cncr.29406)

Bussiere JR, Beer TM, Neiss MB \& Janowsky JS 2005 Androgen deprivation impairs memory in older men. Behavioral Neuroscience 119 1429-1437. (doi:10.1037/0735-7044.119.6.1429)

Cassilhas RC, Viana VAR, Grassmann V, Santos RT, Santos RF, Tufik S \& Mello MT 2007 The impact of resistance exercise on the cognitive function of the elderly. Medicine and Science in Sports and Exercise 39 1401-1407. (doi:10.1249/mss.0b013e318060111f)

Chang YK, Labban JD, Gapin JI \& Etnier JL 2012 The effects of acute exercise on cognitive performance: a meta-analysis. Brain Research 1453 87-101. (doi:10.1016/j.brainres.2012.02.068)

Chao HH, Uchio E, Zhang S, Hu S, Bednarski SR, Luo X, Rose M, Concato J \& Li CR 2012 Effects of androgen deprivation on brain function in prostate cancer patients - a prospective observational cohort analysis. BMC Cancer 12 371-371. (doi:10.1186/1471-240712-371)

Chao HH, Hu S, Ide JS, Uchio E, Zhang S, Rose M, Concato J \& Li CR 2013 Effects of androgen deprivation on cerebral morphometry in prostate cancer patients - an exploratory study. PLOS ONE 8 e72032. (doi:10.1371/journal.pone.0072032)

Cheema BSR, Robergs RA \& Askew CD 2014 Exercise physiologists emerge as allied healthcare professionals in the era of noncommunicable disease pandemics: a report from Australia, 20062012. Sport Medicine 44 869-877. (doi:10.1007/s40279-014-0173-y)

Cherrier MM, Rose AL \& Higano CS 2003 The effects of combined androgen blockade on cognitive function during the first cycle of intermittent androgen suppression in patients with prostate cancer.
(C) 2017 Society for Endocrinology Printed in Great Britain
Published by Bioscientifica Ltd 
Journal of Urology 170 1808-1811. (doi:10.1097/01. ju.0000091640.59812.83)

Cherrier MM, Aubin S, \& Higano CS 2009 Cognitive and mood changes in men undergoing intermittent combined androgen blockade for non-metastatic prostate cancer. Psycho-Oncology 18 237-247. (doi:10.1002/pon.1401)

Cherrier MM, Borghesani PR, Shelton AL \& Higano CS 2010 Changes in neuronal activation patterns in response to androgen deprivation therapy: a pilot study. BMC Cancer 10 1-8. (doi:10.1186/14712407-10-1)

Colcombe S \& Kramer AF 2003 Fitness effects on the cognitive function of older adults: a meta-analytic study. Psychological Science 14 125-130. (doi:10.1111/1467-9280.t01-1-01430)

Cormie P, Newton RU, Spry N, Joseph D, Taaffe DR \& Galvão DA 2013 Safety and efficacy of resistance exercise in prostate cancer patients with bone metastases. Prostate Cancer and Prostatic Diseases 16 328-335. (doi:10.1038/pcan.2013.22)

Cormie P, Chambers SK, Newton RU, Gardiner RA, Spry N, Taaffe DR, Joseph D, Hamid MA, Chong P, Hughes D, et al. 2014a Improving sexual health in men with prostate cancer: randomised controlled trial of exercise and psychosexual therapies. BMC Cancer 14199. (doi:10.1186/1471-2407-14-199)

Cormie P, Galvão DA, Spry N, Joseph D, Taaffe DR \& Newton RU $2014 b$ Functional benefits are sustained after a program of supervised resistance exercise in cancer patients with bone metastases: longitudinal results of a pilot study. Supportive Care in Cancer 6 1537-1548. (doi:10.1007/s00520-013-2103-1)

Cormie P, Galvão DA, Spry N, Joseph D, Chee R, Taaffe DR, Chambers SK \& Newton RU 2015 Can supervised exercise prevent treatment toxicity in patients with prostate cancer initiating androgen-deprivation therapy: a randomised controlled trial. BJU International 2 256. (doi:10.1111/bju.12646)

Cotman CW, Berchtold NC \& Christie L-A 2007 Exercise builds brain health: key roles of growth factor cascades and inflammation. Trends in Neurosciences 30 464-472. (doi:10.1016/j.tins.2007.06.011)

Culos-Reed SN, Robinson JL, Lau H, O'Connor K \& Keats MR 2007 Benefits of a physical activity intervention for men with prostate cancer. Journal of Sport and Exercise Psychology 29 118-127. (doi:10.1123/jsep.29.1.118)

Culos-Reed SN, Robinson JW, Lau H, Stephenson L, Keats M, Norris S, Kline G \& Faris P 2010 Physical activity for men receiving androgen deprivation therapy for prostate cancer: benefits from a 16-week intervention. Supportive Care in Cancer 18 591-599. (doi:10.1007/ s00520-009-0694-3)

Erickson KI, Voss MW, Prakash RS, Basak C, Szabo A, Chaddock L, Kim JS, Heo S, Alves H, White SM, et al. 2011 Exercise training increases size of hippocampus and improves memory. PNAS 108 3017-3022. (doi:10.1073/pnas.1015950108)

Fragala MS, Beyer KS, Jajtner AR, Townsend JR, Pruna GJ, Boone CH, Bohner JD, Fukuda DH, Stout JR \& Hoffman JR 2014 Resistance exercise may improve spatial awareness and reaction in older adults. Journal of Strength and Conditioning Research 28 2079-2087. (doi:10.1519/JSC.0000000000000520)

Galvão DA, Taaffe DR, Spry N, Joseph D \& Newton RU 2009 Cardiovascular and metabolic complications during androgen deprivation: exercise as a potential countermeasure. Prostate Cancer and Prostatic Diseases 12 233-240. (doi:10.1038/pcan.2009.12)

Galvão DA, Taaffe DR, Spry N, Joseph D \& Newton RU 2010 Combined resistance and aerobic exercise program reverses muscle loss in men undergoing androgen suppression therapy for prostate cancer without bone metastases: a randomized controlled trial. Journal of Clinical Oncology 28 340-347.

Gardner JR, Livingston PM \& Fraser SF 2014 Effects of exercise on treatment-related adverse effects for patients with prostate cancer receiving androgen-deprivation therapy: a systematic review. Journal of Clinical Oncology 32 335-346. (doi:10.1200/JCO.2013.49.5523)
Gonzalez BD, Jim HS, Booth-Jones M, Small BJ, Sutton SK, Lin HY, Park JY, Spiess PE, Fishman MN \& Jacobsen PB 2015 Course and predictors of cognitive function in patients with prostate cancer receiving androgen-deprivation therapy: a controlled comparison. Journal of Clinical Oncology 33 2021-2027. (doi:10.1200/ JCO.2014.60.1963)

Green HJ, Pakenham KI, Headley BC, Yaxley J, Nicol DL, Mactaggart PN, Swanson C, Watson RB \& Gardiner RA 2002 Altered cognitive function in men treated for prostate cancer with luteinizing hormone-releasing hormone analogues and cyproterone acetate: a randomized controlled trial. BJU International 90427. (doi:10.1046/j.1464-410X.2002.02917.x)

Green HJ, Pakenham KI, Headley BC, Yaxley J, Nicol DL, Mactaggart PN, Swanson CE, Watson RB \& Gardiner RA 2004 Quality of life compared during pharmacological treatments and clinical monitoring for non-localized prostate cancer: a randomized controlled trial. BJU International 93 975. (doi:10.1111/j.1464410X.2004.04763.x)

Grossmann M \& Zajac JD 2011 Androgen deprivation therapy in men with prostate cancer: how should the side effects be monitored and treated? Clinical Endocrinology 74 289-293. (doi:10.1111/j.13652265.2010.03939.x)

Grossmann M, Cheung AS \& Zajac JD 2013 Androgens and prostate cancer; pathogenesis and deprivation therapy. Bailliere's Best Practice and Research in Clinical Endocrinology and Metabolism 27603. (doi:10.1016/j.beem.2013.05.001)

Hamer M \& Chida Y 2009 Physical activity and risk of neurodegenerative disease: a systematic review of prospective evidence. Psychological Medicine 39 3-11. (doi:10.1017/ S0033291708003681)

Harvey PD 2012 Clinical applications of neuropsychological assessment. Dialogues in Clinical Neuroscience 14 91-99.

Janelsins MC, Kesler SR, Ahles TA \& Morrow GR 2014 Prevalence, mechanisms, and management of cancer-related cognitive impairment. International Review of Psychiatry 26 102-113. (doi:10.31 09/09540261.2013.864260)

Jenkins VA, Bloomfield DJ, Shilling VM \& Edginton TL 2005 Does neoadjuvant hormone therapy for early prostate cancer affect cognition? Results from a pilot study. BJU International 96 48-53. (doi:10.1111/j.1464-410X.2005.05565.x)

Keogh JWL \& MacLeod RD 2012 Body composition, physical fitness, functional performance, quality of life, and fatigue benefits of exercise for prostate cancer patients: a systematic review. Journal of Pain and Symptom Management 43 96-110. (doi:10.1016/j. jpainsymman.2011.03.006)

Kulkarni D \& Moningi S 2015 Neurocognitive function monitoring. Journal of Neuroanaesthesiology in Critical Care 2 246-256. (doi:10.4103/2348-0548.165055)

Liu-Ambrose T, Nagamatsu LS, Graf P, Beattie BL, Ashe MC \& Handy TC 2010 Resistance training and executive functions: a 12-month randomized controlled trial. Archives of Internal Medicine 170 170-178. (doi:10.1001/archinternmed.2009.494)

Livingston PM, Salmon J, Courneya KS, Gaskin CJ, Craike M, Botti M, Broadbent S \& Kent B 2011 Efficacy of a referral and physical activity program for survivors of prostate cancer (ENGAGE): rationale and design for a cluster randomised controlled trial. BMC Cancer 11 237-247. (doi:10.1186/14712407-11-237)

Livingston PM, Craike MJ, Salmon J, Courneya KS, Gaskin CJ, Fraser SF, Mohebbi M, Broadbent S, Botti M \& Kent B 2015 Effects of a clinician referral and exercise program for men who have completed active treatment for prostate cancer: a multicenter cluster randomized controlled trial (ENGAGE). Cancer 121 2646-2654. (doi:10.1002/cncr.29385)

Matousek RH \& Sherwin BB 2010 A randomized controlled trial of addback estrogen or placebo on cognition in men with prostate cancer

Published by Bioscientifica Ltd. 
receiving an antiandrogen and a gonadotropin-releasing hormone analog. Psychoneuroendocrinology 35 215-225. (doi:10.1016/j. psyneuen.2009.06.012

McGinty HL, Phillips KM, Jim HSL, Cessna JM, Asvat Y, Cases MG, Small BJ \& Jacobsen PB 2014 Cognitive functioning in men receiving androgen deprivation therapy for prostate cancer: a systematic review and meta-analysis. Supportive Care in Cancer 22 2271-2280. (doi:10.1007/s00520-014-2285-1)

Miki E, Kataoka T \& Okamura H 2014 Feasibility and efficacy of speedfeedback therapy with a bicycle ergometer on cognitive function in elderly cancer patients in Japan. Psycho-Oncology 23 906-913. (doi:10.1002/pon.3501)

Mohile SG, Lacy M, Rodin M, Bylow K, Dale W, Meager MR \& Stadler WM 2010 Cognitive effects of androgen deprivation therapy in an older cohort of men with prostate cancer. Critical Reviews in Oncology/Hematology 75 152-159. (doi:10.1016/j. critrevonc.2010.06.009)

Nagamatsu LS, Handy TC, Hsu C, Voss M \& Liu-Ambrose T 2012 REsistance training promotes cognitive and functional brain plasticity in seniors with probable mild cognitive impairment. Archives of Internal Medicine 172 666-668. (doi:10.1001/ archinternmed.2012.379)

Nead KT, Gaskin G, Chester C, Swisher-McClure S, Dudley JT, Leeper NJ \& Shah NH 2016 Androgen deprivation therapy and future Alzheimer's disease risk. Journal of Clinical Oncology 34 566-571. (doi:10.1200/JCO.2015.63.6266)

Nelson CJ, Lee JS, Gamboa MC \& Roth AJ 2008 Cognitive effects of hormone therapy in men with prostate cancer. Cancer $\mathbf{1 3}$ 1097-1106. (doi:10.1002/cncr.23658)

Nguyen PL, Alibhai SMH, Basaria S, D’Amico AV, Kantoff PW, Keating NL, Penson DF, Rosario DJ, Tombal B \& Smith MR 2015 Platinum Priority - collaborative review - prostate cancer: adverse effects of androgen deprivation therapy and strategies to mitigate them. European Urology 67 825-836. (doi:10.1016/j.eururo.2014.07.010)

Oh B, Butow PN, Mullan BA, Clarke SJ, Beale PJ, Pavlakis N, Lee MS, Rosenthal DS, Larkey L \& Vardy J 2012 Effect of medical Qigong on cognitive function, quality of life, and a biomarker of inflammation in cancer patients: a randomized controlled trial. Supportive Care in Cancer 20 1235-1242. (doi:10.1007/s00520-011-1209-6)

Papachristou E, Ramsay SE, Lennon LT, Papacosta O, Iliffe S, Whincup PH \& Wannamethee SG 2015 The relationships between body composition characteristics and cognitive functioning in a population-based sample of older British men. BMC Geriatrics 15 172. (doi:10.1186/s12877-015-0169-y)

Rock CL, Doyle C, Demark-Wahnefried W, Meyerhardt J, Courneya KS, Schwartz AL, Bandera EV, Hamilton KK, Grant B, McCullough M, et al. 2012 Nutrition and physical activity guidelines for cancer survivors. CA: A Cancer Journal for Clinicians 62 243-274. (doi:10.3322/caac.21142)

Roldán-Tapia L, García J, Cánovas R \& León I 2012 Cognitive reserve, age, and their relation to attentional and executive functions. Applied Neuropsychology: Adult 19 2-8. (doi:10.1080/09084282.2011.595458)

Roque FR, Hernanz R, Salaices M \& Briones AM 2013 Exercise training and cardiometabolic diseases: focus on the vascular system. Current Hypertension Reports 15 204-214. (doi:10.1007/s11906-013-0336-5)
Salminen E, Portin R, Korpela J, Backman H, Parvinen LM, Helenius H \& Nurmi M 2003 Androgen deprivation and cognition in prostate cancer. British Journal of Cancer 89 971-976. (doi:10.1038/sj. bjc.6601235)

Salminen E, Aki Koskinen HH, \& Nurmi M 2004 Associations between serum testosterone fall and cognitive function in prostate cancer patients. Clinical Cancer Research 10 7575-7582. (doi:10.1158/10780432.CCR-04-0750)

Salthouse TA 2009 When does age-related cognitive decline begin? Neurobiology of Aging 30 507-514. (doi:10.1016/j. neurobiolaging.2008.09.023)

Schmitz KH, Courneya KS, Matthews C, Demark-Wahnefried W, Galvao DA, Pinto BM, Irwin ML, Wolin KY, Segal RJ, Lucia A, et al. 2010 American College of Sports Medicine roundtable on exercise guidelines for cancer survivors. Medicine and Science in Sports and Exercise 42 1409-1426. (doi:10.1249/MSS.0b013e3181e0c112)

Shahinian VB, Kuo YF, Freeman JL, Orihuela E \& Goodwin JS 2005 Increasing use of gonadotropin-releasing hormone agonists for the treatment of localized prostate carcinoma. Cancer 103 1615-1624. (doi:10.1002/cncr.20955)

Tan WW, Hechman MG, Vishnu P, Crook JE, Younkin LH, Covil EG, Ferman TJ, Graff-Radford NR, Younkin SG, Smallridge RC, et al. 2013 Effect of leuprolide on serum amyloid-beta peptide levels and memory in patients with prostate cancer with biochemical recurrence. Urology 81 150-154. (doi:10.1016/j. urology.2012.08.066)

Trost LW, Serefoglu E, Gokce A, Linder BJ, Sartor AO \& Hellstrom WJ 2013 Androgen deprivation therapy impact on quality of life and cardiovascular health, monitoring therapeutic replacement. Journal of Sexual Medicine 10 84-101. (doi:10.1111/jsm.12036)

Voelcker-Rehage C, Godde B \& Staudinger UM 2010 Physical and motor fitness are both related to cognition in old age. European Journal of Neuroscience 31 167-176. (doi:10.1111/j.1460-9568.2009.07014.x)

Voss MW, Prakash RS, Erickson KI, Basak C, Chaddock L, Kim JS, Alves H, Heo S, Szabo AN \& White SM 2010 Plasticity of brain networks in a randomized intervention trial of exercise training in older adults. Frontiers in Aging Neuroscience 2 32. (doi:10.3389/ fnagi.2010.00032)

Wefel JS, Vardy J, Ahles T \& Schagen SB 2011 International Cognition and Cancer Task Force recommendations to harmonise studies of cognitive function in patients with cancer. Lancet Oncology 7703. (doi:10.1016/S1470-2045(10)70294-1)

Wefel JS, Kesler SR, Noll KR \& Schagen SB 2015 Clinical characteristics, pathophysiology, and management of noncentral nervous system cancer-related cognitive impairment in adults. CA: A Cancer Journal for Clinicians 65 123-138. (doi:10.3322/caac.21258)

Yu-Kai C, Chien-Yu P, Feng-Tzu C, Chia-Liang T \& Chi-Chang H 2012 Effect of resistance-exercise training on cognitive function in healthy older adults: a review. Journal of Aging and Physical Activity 20 497-517. (doi:10.1123/japa.20.4.497)

Zimmer P, Baumann FT, Oberste M, Wright P, Garthe A, Schenk A, Elter T, Galvao DA, Bloch W, Hübner ST, et al. 2016 Effects of exercise interventions and physical activity behavior on cancer related cognitive impairments: a systematic review. BioMed Research International 2016 article ID 1820954. (doi:10.1155/2016/1820954)

Received in final form 12 February 2017

Accepted 16 February 2017

Accepted Preprint published online 16 February 2017 http://erc.endocrinology-journals.org DOI: $10.1530 /$ ERC-16-0493
(C) 2017 Society for Endocrinology Printed in Great Britain
Published by Bioscientifica Ltd. 